Washington, DC, 1996).

8. Panasik, N., Jr, Eberhardt, E. S., Edison, A. S., Powell, D. R. \& Raines, R. T. Int. J. Pept. Protein Res. 44, 262-269 (1994).

9. Eberhardt, E. S., Panasik, N., Jr \& Raines, R. T. J. Am. Chem. Soc. 118, 12261-12266 (1996).

10. Semisotnov, G. V. et al. Biopolymers 31, 119-128 (1991).

11.Shah, N. K., Ramshaw, J. A. M., Kirkpatrick, A., Shah, C. \&

Brodsky, B. Biochemistry 35, 10262-10268 (1996).

12. Werkmeister, J. A. \& Ramshaw, J. A. M. (eds) Collagen

Biomaterials (Elsevier Science, Barking, Essex, 1992).

\section{Gene translocation links insects and crustaceans}

The evolutionary relationships among the four major lineages of arthropods remain controversial, despite extensive study. We report here a derived gene rearrangement common to insects and crustaceans but absent in the other arthropod groups. This finding strongly supports an insectcrustacean evolutionary lineage that is separate from those leading to myriapods and chelicerates.

The four major arthropod groups are Chelicerata (such as scorpions and horseshoe crabs), Crustacea (such as crabs and brine shrimp), Myriapoda (such as centipedes and millipedes), and Insecta (such as flies and beetles). Much of arthropod evolution remains contentious but, until recently, there has been general agreement that myriapods are the closest relatives of insects, forming a group known as the Atelocerata.

However, several recent morphological and molecular comparisons suggest that crustaceans, rather than myriapods, are the sister group to insects. If this is the case, some characteristics shared by insects and myriapods (such as a tracheal system for respiration, Malpighian tubules for excretion, and unbranched legs) then become examples of convergent evolution, perhaps as adaptations to life on land. Similar features are found among terrestrial chelicerates, where their occurrence is already viewed as convergent.

In a previous study ${ }^{1}$, we reported that insects and crustaceans share a derived location for the gene encoding mitochondrial leucine transfer RNA, designated $L(U U R)$, as compared with its primitive location in a chelicerate, an onychophoran, and several non-arthropod metazoans. However, in that study we were unable to associate a myriapod (Thyropygus) with either group.

Now, further mitochondrial DNA (mtDNA) sequence for Thyropygus and for three other myriapod species allows us to make that association. These four myriapods share the gene arrangement LrRNA$L(C U N)-L(U U R)-N D 1$, which is almost certainly primitive ${ }^{1}$. Our earlier misinterpretation of the Thyropygus sequence was due to a similarity of the amino-acid sequence

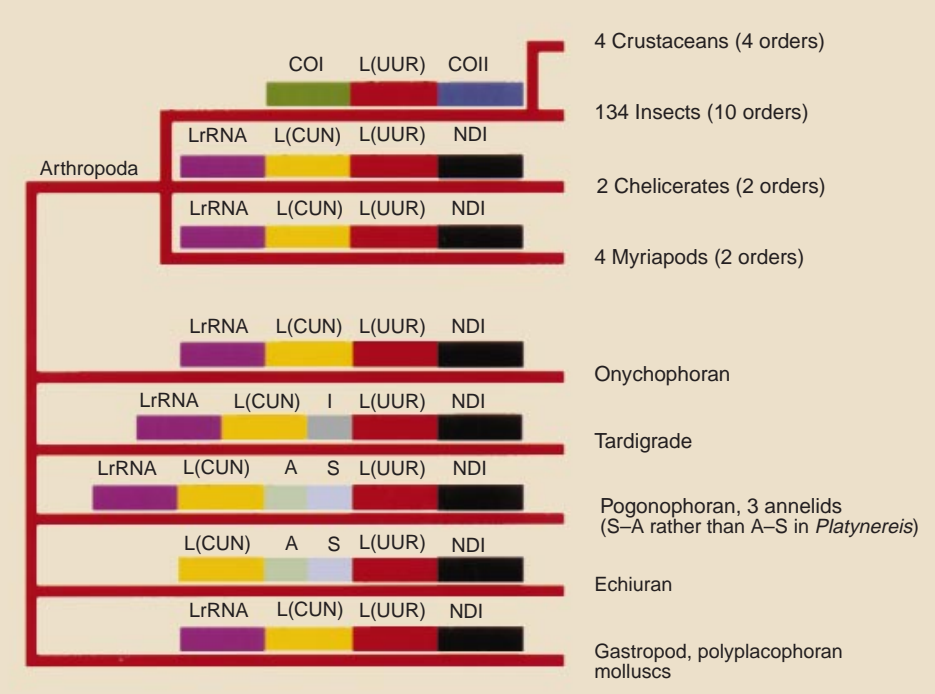

Figure 1 Relative location of the L(UUR) gene for 153 taxa. The primitive location is identified in many nonarthropods and is retained in the mitochondrial genomes of the chelicerates and myriapods. An insect-crustacean clade is identified by the shared translocation of $L(U U R)$ to the position between $\mathrm{CO}$ and COIl. For 49 of these insect taxa, only the gene arrangement $L(U U R)-C O l l$ has actually been determined ${ }^{8}$. For the chelicerates, myriapods, onychophoran, tardigrade, and echiuran, COI-COll are directly adjacent without any intervening tRNA genes; other taxa have an unrelated tRNA here. The three crustaceans and ten insects share the gene arrangement LIRNA-L(CUN)-ND1. For all arthropods for which the relative locations of these two gene blocks have been determined ${ }^{2-7}$, they are separated by more than 2.5 kilobases and are encoded on opposite DNA strands. Data are from published sources for three crustaceans (Homarus', Daphnia', Artemia $^{3}$ ), the insects ${ }^{8}$ (additional citations available from $J \mathrm{~B}$ ), a chelicerate (Limulus ${ }^{2}$ ), onychophoran (Euperipatoides'), annelid (Lumbricus $\left.{ }^{9}\right)$, gastropod (Plicopurpura') and polyplacophoran (Katharina $\left.{ }^{10}\right)$. Sequences determined here are for a remipede crustacean (Speleonectes), chelicerate (Pandinus), four myriapods (Thyropygus, Lithobius, Spirostrephon, Narceus), tardigrade (Thulinia), pogonophoran (Galatheolinum), two annelids (Helobdella, Platynereis) and echiuran (Urechis). Sequences were determined from DNA fragments amplified using the polymerase chain reaction with primers made to conserved gene regions. Mitochondrial DNA typically contains 37 genes, only a subset of which is shown here (gene abbreviations are as published ${ }^{9}$.

inferred from the terminal 39 nucleotides of the L(UUR) gene. These nucleotides are in frame with the actual start site of the ND1 gene and match $5 / 13$ of the corresponding residues of the ND1 gene in Drosophila.

The most parsimonious explanation for the gene arrangement data (Fig. 1) is that a single translocation of the L(UUR) gene occurred in a common lineage that led, after it split from the other lineages shown, to crustaceans and insects. This signature of common evolutionary history persists in the $m t D N A s$ of these groups today.

If myriapods and insects were sister groups, either this tRNA translocation would need to have occurred twice identically in the lineages leading to insects and crustaceans, or it would need to have reverted to its primitive state in the myriapods. Each of these explanations would require an identical complex process.

Furthermore, this gene has translocated to a position remote from the original one. So the process is not a simple exchange of positions between neighbouring genes, nor does it involve genes adjacent to a large non-coding region, either of which might increase the frequency of gene rearrangement.
Another argument against the change being convergent is the infrequency of rearrangements among arthropod mitochondrial DNAs. Complete arrangements of all 37 mitochondrial genes have been determined for six arthropod genera: one chelicerate (Limulus $\left.{ }^{2}\right)$; one crustacean $\left(\right.$ Artemia $\left.^{3}\right)$; and four insect (Drosophila ${ }^{4}$, Locusta $^{5}$, Anopheles ${ }^{6}$, Apis $^{7}$ ). The Drosophila arrangement differs from that of Limulus only in the location of $L(U U R)$, from that of Artemia only in the location of the tRNA gene block $I-Q$, and from those of Locusta, Anopheles, and Apis by one, two and eight tRNA translocations, respectively. There is no evidence of 'hot spots' for tRNA gene translocations in these genera, although the sample size is small.

Rearrangements of the 37 genes typical of metazoan mtDNA appear to be unique, rare events, unlikely to be duplicated by convergence, stable once they have occurred, and easily recognized because of the homology of mitochondrial genes across the Metazoa ${ }^{1}$. Our phylogenetic interpretation requires no convergence in any taxon for which data are available (more than 200 taxa representing 8 phyla).

We believe that this synapomorphy 
strongly supports an insect-crustacean clade that excludes myriapods. Also, we anticipate that further study of the relative arrangements of the genes in metazoan mtDNA will help to clarify many other higher-level evolutionary relationships.

\section{Jeffrey L. Boore, Dennis V. Lavrov,}

Wesley M. Brown

Department of Biology, University of Michigan, 830 North University Avenue, Ann Arbor,

Michigan 48109, USA

e-mail: jboore@umich.edu

1. Boore, J. L., Collins, T. M., Stanton, D., Daehler, L. L. \& Brown, W. M. Nature 376, 163-165 (1995).

2. Staton, J. L., Daehler, L. L. \& Brown, W. M. Mol. Biol. Evol. 14, 867-874 (1997).

3. Valverde, J., Batuecas, B., Moratilla, C., Marco, R. \& Garesse, R. J. Mol. Evol. 39, 400-408 (1994).

4. Clary, D. O. \& Wolstenholme, D. R. J. Mol. Evol. 22, 252-271 (1985)

5. Flook, P., Rowell, C. H. F. \& Gellissen, G. J. Mol. Evol. 41, 928-941 (1995).

6. Beard, C. B., Hamm, D. M. \& Collins, F .H. Insect Mol. Biol. 2, 103-124 (1993).

7. Crozier, R.H. \& Crozier, Y. C. Genetics 133, 97-117 (1993).

8. Boore, J. L. in Current Topics on Molecular Evolution (eds Nei, M. \& Takahata, N.) 69-78 (Institute of Molecular Evolutionary Genetics, Pennsylvania State Univ., State College, PA, 1996).

9. Boore, J. L. \& Brown, W. M. Genetics 141, 305-319 (1995).

10. Boore, J. L. \& Brown, W. M. Genetics 138, 423-443 (1994).

\section{What's so special about figs?}

Fruit-eating animals regularly prefer to eat figs even when other food is abundant. We propose that high calcium levels contribute to the desirability of figs as food for many forest animals.

There has been debate over the nutritional significance of the fig in the diet of frugivores $^{1,2}$ and over its importance as a 'keystone' species ${ }^{3-6}$. We compared the mineral composition of figs and other fruits from Belize, Indonesia and Uganda, and found that there was more than three times as much calcium in figs as in other fruits.

We analysed the mineral content of figs and other non-domestic fruit species from the neotropical, African and Asian regions

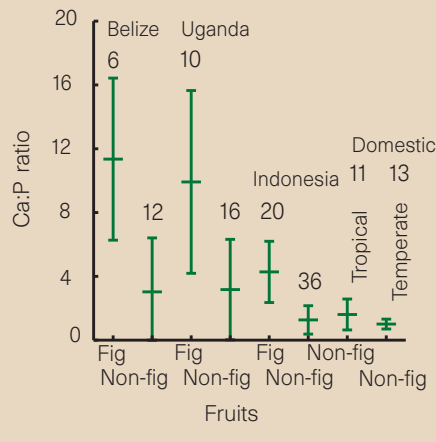

Figure 1 Mean ( \pm s.d.) calcium-to-phosphorus ratios for fig and wild non-fig fruits from Belize, Indonesia, and Uganda, and temperate and tropical domestic fruits. Numbers indicate species per sample.

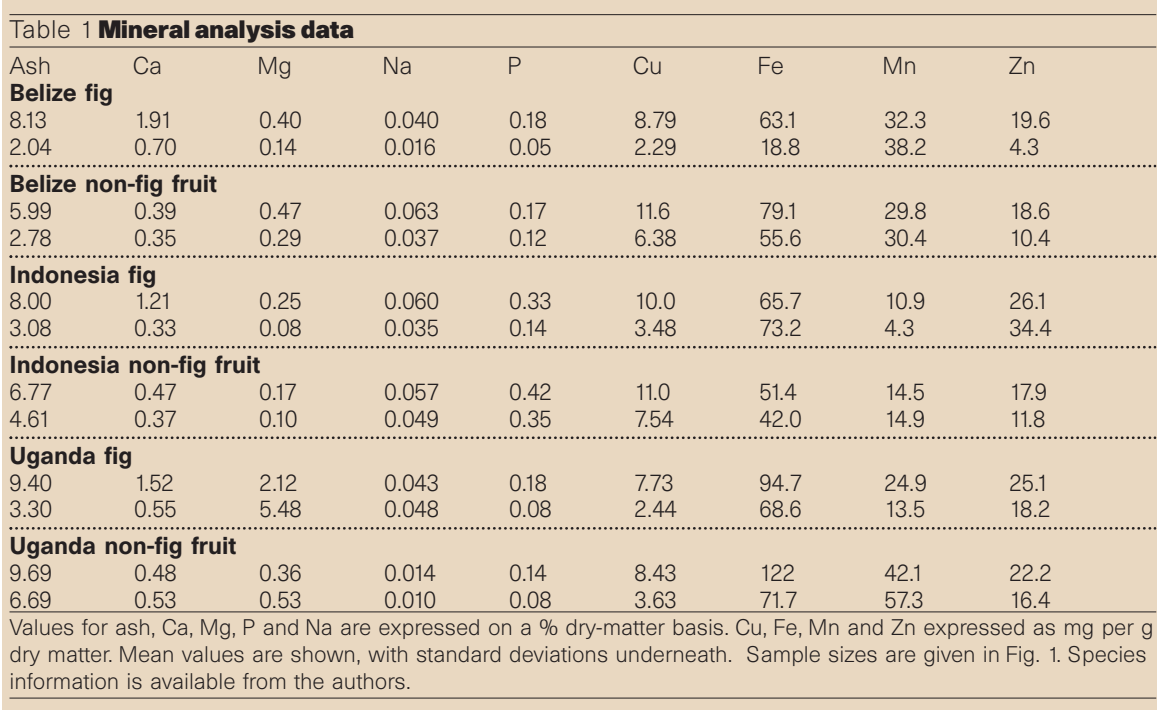

(Table 1), and 11 tropical and 13 temperate domestic fruit species. Regional differences were evident in the calcium, magnesium, iron, manganese, phosphorus and sodium content of all the fruits. This may have reflected varying soil fertility between collection sites.

However, between fig and non-fig fruits, differences in mineral concentrations were restricted to calcium. On average, figs contained calcium levels 3.2 times higher than other fruits - levels high enough to promote eggshell deposition in birds, and bone growth in birds and mammals ${ }^{7,8}$. Also, the ratio of calcium to phosphorus (a measure of calcium availability ${ }^{7,9}$ ) was 3.7 times higher in figs than in other fruits (Fig. 1). Figs from Sulawesi, Indonesia contained more calcium relative to the calcium availability in the soils, indicating that fig trees may selectively absorb calcium or allocate calcium to fruits.

Previous studies have shown that the protein, carbohydrate and lipid content of figs ${ }^{1,2}$ are variable and not exceptionally high. Our study indicates that calcium concentration relative to phosphorus may be an important criterion for selection of the fruit.

Growth processes and egg-laying are accompanied by a rise in requirements for calcium and phosphorus ${ }^{7,8}$ to lay down eggshell, aid metabolism, construct nucleic acids and form bone. Because most non-fig fruits, as well as seeds and invertebrates, are poor sources of calcium, many birds and mammals rely on calcium supplements such as mollusc shells, bone or soil to ensure adequate dietary calcium ${ }^{7,10,11}$. Others consume large quantities of figs throughout the year $^{5,6,12}$. The biological availability of calcium in figs has not been determined, but animals whose diets are rich in figs are unlikely to suffer from calcium deficiency.

Terborgh $^{3}$ and others ${ }^{5,6,12}$ suggest that figs constitute a 'keystone' plant resource for fruit-eating birds and mammals throughout the tropics. Figs display inter- and intraspe- cific asynchrony in fruiting, tend to produce large crops, and show low interannual variation in fruit production ${ }^{13}$. These fruiting patterns make figs a reliable food source during times of general fruit scarcity.

Our results indicate that figs may be important throughout the year for maintaining an adequate balance of calcium among fruit-eating animals, thus fulfilling the role of a keystone plant resource for many animal species. These findings also suggest that the concentrations of specific minerals represent an important nutritional criterion for evaluating dietary choices across taxonomic groups and pantropical ecosystems.

Timothy G. O'Brien, Margaret F. Kinnaird,

\section{Ellen S. Dierenfeld}

Wildlife Conservation Society,

Bronx, New York 10460, USA

e-mail:WCS-IP@indo.net.id

Nancy L. Conklin-Brittain,

Richard W. Wrangham

Anthropology Department, Harvard University,

Cambridge, Massachusetts 02138, USA

\section{Scott C. Silver}

Department of Biological Sciences,

Fordham University, Bronx, New York 10460, USA

1. Concklin, N. L. \& Wrangham, R. W. Biochem. Syst. Ecol. 22, 137-151 (1994)

2. Bronstein, J. L. \& Hoffman, K. Oikos 49, 261-268 (1987).

3. Terborgh, J. Conservation Biology: The Science of Scarcity and Diversity (ed. Soule, M.) 330-334 (Sinauer, Sunderland, MA, 1986)

4. Gautier, A. \& Michaloud, G. Ecology, 70, 1826-1833 (1989).

5. Lambert, F. \& Marshall, G. J. Ecology 79, 793-809 (1991).

6. Kalko, E. J. Biogeogr., 23, 565-576 (1996).

7. Robbins, C. T. Wildlife Feeding and Nutrition (Academic, New York, 1993).

8. National Research Council. Nutrient Requirements of Laboratory Animals, Publ. No. 2767 (National Academy of Sciences, Washington DC, 1978).

9. National Research Council. Mineral Tolerance of Domestic Animals (National Academy of Sciences, Washington DC, 1980 ).

10. Graveland, J. \& van der Wal, R. Oecologia 105, 351-360 (1996).

11. Barclay, R. M. R. Symp. Zool. Soc. Lond. 67, 245-258 (1995).

12. Kinnaird, M. F., O’Brien, T. G. \& Suryadi, S. Auk 113, 431-440 (1996).

13. Janzen, D. H. Annu. Rev. Ecol. Syst. 10, 13-52 (1979). 